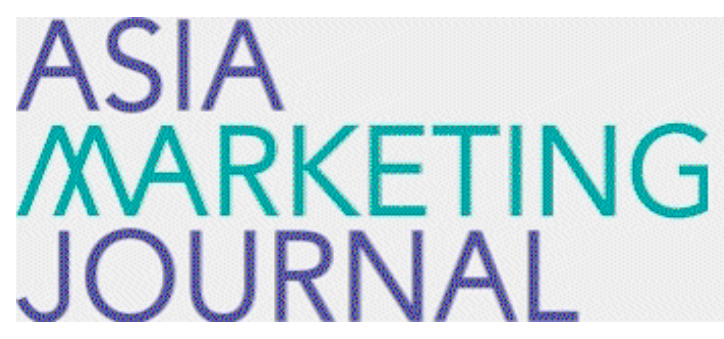

ASIA MARKETING JOURNAL

Volume 18 | Issue 4

Article 7

$1-31-2017$

\title{
Television Shopping at Home to Alleviate Loneliness Among Older Consumers
}

Min-Sun Lee

Jihye Park

Follow this and additional works at: https://amj.kma.re.kr/journal

Part of the Marketing Commons

\section{Recommended Citation}

Lee, Min-Sun and Park, Jihye (2017) "Television Shopping at Home to Alleviate Loneliness Among Older Consumers," Asia Marketing Journal: Vol. 18 : Iss. 4 , Article 7.

Available at: https://doi.org/10.15830/amj.2017.18.4.139

This Article is brought to you for free and open access by Asia Marketing Journal. It has been accepted for inclusion in Asia Marketing Journal by an authorized editor of Asia Marketing Journal. 


\title{
Television Shopping at Home to Alleviate Loneliness Among Older Consumers*
}

\author{
Min-Sun Lee** \\ Jihye Park ${ }^{* * *}$
}

\begin{abstract}
Despite widespread awareness of the importance of a middle-aging and older consumer market, it is surprising that very little research has been conducted on their in-home shopping behavior. Therefore, this study focused on middle-aging and older female television home shoppers and examined the effects of persuasive mentions of the show host and parasocial interaction on social involvement, perceived loneliness, mood, perceived risk and unplanned buying tendency. A total of 109 middleaged and older female television shoppers responded. Results of path analysis revealed that persuasive mentions did not influence parasocial interaction. However, as middle-aging and older consumers more para-socially interacted with the host, they were likely to use television shopping for alleviating loneliness. Practical and theoretical implications were discussed.
\end{abstract}

Key words: Older consumers, television shopping, parasocial interaction, loneliness

\section{Introduction}

A remarkable increase in the growth of the older population has become one of the major market trends in the US. Women aged 55 and over are considered a market having much po- tential due to their buying power (Schein and Haruvi 2014). For middle-aging and older shoppers, television shopping is an attractive shopping venue with several unique benefits such as ease in finding diverse clothing sizes and convenience to shop at home. InfoScout (2016) $\mathrm{re}^{-}$ ported that nearly $48 \%$ of the television shop-

\footnotetext{
* This work was based on Min-Sun Lee's master's thesis at Iowa State University. Jihye Park was a formal advisor for her master's thesis at Iowa State University.

This work was partially supported by Hankuk University of Foreign Studies Research Fund of 2016.

*** Lecturer, College of Natural Sciences Incheon National University (minsun1107@gmail.com)

*** Professor of Marketing College of Business Hankuk University of Foreign Studies (jihyepark@hufs.ac.kr), Corresponding Author
} 
pers were over the age of 55. Body shape changes (e.g., thickened waist, enlarged hips, protruding abdomen, and drooping bustline) make them feel difficult to find apparel that fits well in traditional retail stores, which focus on younger consumers (Kaiser and Chandler 1984). Physical and psychological factors such as body shape changes, limited mobility, and loneliness also motivate older shoppers to watch television shopping programs (Lim and Kim 2011). Driving or walking discourages older consumers to shop at traditional malls or retail stores.

In television shopping programs in the US, the host typically leads an one-hour program and presents the product in detail. The host makes the viewers feel as if he/she is talking directly to them. The host often communicates some common life issues of the viewers, such as their families, interests, and personal feelings about themselves (Skumanich and Kintsfather 1998). During television shopping shows, viewers feel a close relationship with the host. Older women who have limited opportunities for socialization are likely to turn to television shopping programs to fulfill social needs and, hence, are likely to para-socially interact with the hosts (Rubin, Perse, and Powell 1985). Similarly, middle-aging and older shoppers place greater importance on interactions and relationships with the salespeople when purchasing a product in the traditional retail store (Johnson-Hillery and Kang 1997). They tend to perceive friendships with the television shopping show host as an alternative form of social interaction. A perceived relationship with hosts from television shopping programs can minimize loneliness, evoke positive moods, and ultimately influence customers' purchase tendency (Johnson-Hillery and Kang 1997; Kim, Kang, and Kim 2005). Persuasive mentions of the host such as reciprocation, consistency, social proof, liking, authority, and scarcity motivate viewers to make a purchase and often result in impulse purchase (Fritchie and Johnson 2003).

Despite widespread awareness of the importance of a middle-aging and older consumer market, it is surprising that very little research has been conducted on their in-home shopping behavior. Therefore, this study focused on middleaging and older female television shoppers and examined the effects of persuasive mentions of the show host and parasocial interaction in the television shopping environment. Causal relationships among parasocial interactions, social involvement, perceived loneliness, positive mood, perceived risk and unplanned buying were examined.

\section{Theoretical Background}

\subsection{Parasocial Interaction}

In television shopping programs, the host tends to use various communication approaches 
to evoke viewers' purchase intention. The informal and friendly verbal style of the television shopping show host can create the illusion of an inter-personal relationship with the host for viewers, which is defined as parasocial interaction (Grant et al. 1991; Papa et al. 2000). Parasocial interaction is often developed with media personalities such as actors, newscasters, and show hosts. Media personae share their opinions with the viewers and sometimes communicate directly over the phone (e.g., Auter and Moore 1993; Fritchie and Johnson 2003; Papa et al. 2000; Skumanich and Kintsfather 1998; Stephens et al. 1996). Parasocial interaction is an important motivation for watching home shopping programs (Auter and Moore 1993) and may induce viewers to watch more television shows (Conway and Rubin 1991). The stronger the parasocial interaction, the more television news the viewers watch (Levy 1979; Rubin et al. 1985).

Television shopping show hosts tend to use persuasive mentions to develop parasocial interactions with their customers as well as to motivate a purchase. The hosts often mention reciprocation (e.g., the host provides free merchandise or gift), consistency (e.g., the host explains how a product matches what consumers want), social proof (e.g., the product is the best seller), liking (e.g., the host is not only a likeable person, but also can be seen as a friend), authority (e.g., the host leads a program with an expert co-host, such as a designer or celeb- rity), and scarcity (e.g., the host urges the limited number of the products or the limited time to purchase) in the television shopping programs. Social proof and scarcity mentions were the most commonly used by the hosts (Fritchie and Johnson 2003). Persuasive mentions are executed through informal and friendly conversations of the host. Viewers may feel the hosts are friends (Cialdini and Goldstein 2002) and tend to interact with the program hosts. Several researchers (e.g., Auter and Moore 1993) argued that television shopping show hosts encourage parasocial interaction, using a friendly verbal style. Through parasocial interaction, customers may seek guidance for purchasing products and see media personalities as friends (Rubin et al. 1985). Therefore, it is expected that persuasive mentions of the host lead to parasocial interactions of the older consumers. The following hypothesis is developed.

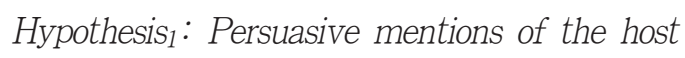
have a positive effect on parasocial interaction.

\subsection{Effect of Parasocial Interaction on Social Involvement, Positive Mood, and Loneliness}

Older people tend to have fewer opportunities of social activities and experience fewer social interactions, due to limited mobility and health (Rahtz, Sirgy, and Meadow 1989). As they age, they are less likely to engage in interactions 
with their families (Smith and Moschis 1985). Older consumers with less social interactions are more willing to listen to what a telemarketer says over the phone (Lee and Geistfeld 1999) and tend to have parasocial relationships with media personae as an alternative form of social involvement (Levy 1979). Television shopping helps older consumers feel more socially involved. It simulates the perceived interpersonal relationship between hosts and viewers (Fritchie and Johnson 2003). During television shopping, parasocial interactions between viewers and the hosts may lead the viewers to feel that the hosts are friends.

Some researchers emphasized the effect of parasocial interaction on viewers' social activities. Papa et al. (2000) found that parasocial interaction can facilitate behavioral changes among media viewers. People with greater parasocial interactions were more likely to have a conversation with other community members about the content of media programs they watched than those who interacted less (Papa et al. 2000). People with less social interactions may develop parasocial relationships with media personae as an alternative form of social involvement. Levy (1979) studied the parasocial interaction between audience and television newscasters, and found that the more social interaction opportunities an individual has, the less likely a person will engage in parasocial interactions with newscasters. Thus, television-shopping activities can enhance older consumers' perceived social involvement (Cialdini and Goldstein 2002). Therefore, the following hypothesis is developed.

Hypothesis 2 : Parasocial interactions have a positive effect on perceived social involvement.

Mood affects product evaluations and judgments of how much they like the product. A negative mood state can lead to a less favorable evaluation of the situation (e.g., decreased buying intention); whereas, a positive mood state can result in a more favorable evaluation of the situation (e.g., increased buying intention) (e.g., Gorn, Goldberg, and Basu 1993). Andrade (2005) found that people were more likely to try a new product when they were in a positive mood state than in a negative mood state.

Shoppers' mood is often influenced by their relationships with the salespeople in the store. A positive mood is enhanced when consumers experience good service from salespeople (Diener 2000; Johnson-Hillery and Kang 1997). Older people are even more sensitive to salespeople's treatment than younger consumers (Braus 1990). They tend to shop more in stores where salespeople know them. When older people have dynamic interactions with salespeople, they are likely to feel better and be in a positive mood (Johnson-Hillery and Kang 1997). In television shopping, because older people who have limited opportunities for social interaction (Rubin et al. 1985) and less social involvement (Gibson 
2000) tend to interact with the hosts, they are more likely to develop a close relationship with the host, feel a sense of social involvement that fulfill their social needs, and, in turn, feel pleasure. Therefore, it is expected that parasocial interactions with the hosts in the television shopping environment may lead to a positive mood state for older consumers. The following hypothesis is developed:

Hypothesis 3 : Parasocial interaction has a positive effect on positive mood.

Loneliness often caused by less social interactions and limited leisure activities increased with age (Nordlund 1978). Life events, such as retirement and death of a spouse and/or friends, contribute to loneliness (Manthorpe 2005). Women more than men were likely to report to be lonely. Older people may experience different forms of loneliness, due to the 'biogenic' and 'sociogenic' problems of aging as compared to younger people (Gibson 2000). A biogenic problem is caused by the natural physical deterioration during the aging process, such as decline in physical robustness, less efficient sight and hearing, weakened muscles and joints, and dysfunctional internal organs (Gibson 2000). Even though older people want to continue their active lifestyle, these biogenic problems may make them practically housebound. A sociogenic problem causing loneliness in later life is related to social relationships of older people (Gibson 2000).
Because of the longer life expectancy of women compared to men, there may be more and more widows in later life. Absence of a husband, as well as few chances of finding a male companion, may cause loneliness for older women. Retirement also can cause loneliness due to the decline of social relationships with others who shared interests and gossip (Gibson 2000).

Older women with fewer social interactions and spending more time alone tend to do television home shopping to alleviate loneliness (Park and Lennon 2004). They enjoy recreational experiences from television shopping through indirect conversation and a perceived close relationship with the affable and accessible program hosts. Television shoppers feel a type of friendship with the host (McDonald 1995). For those who live alone, interacting with the hosts can be an alternative form of social activity (Kang and Ridgway 1996). Even in the traditional retail stores, elderly consumers, who tend to be socially-isolated, are more likely to interact with salespeople than younger consumers (Levy 1979). Therefore, as older consumers parasocially interact with the host, they are likely to feel less lonely. Following hypothesis is developed.

Hypothesis $_{4}$ : Parasocial interaction has a negative effect on perceived loneliness

People may feel lonely when they perceive a lack of social participation (Rubin et al. 1985). Older consumers, who had less social involve- 
ment, were likely to feel lonelier than those who had greater social involvement (Kim et al. 2005). Previous literature showed a strong inverse relationship between social involvement and loneliness among older people. Increasing and maintaining levels of social involvement may alleviate loneliness among older people (Cattan, White, Bond, and Learmouth 2005). Based on the literature, it is expected that perceived social involvement of older consumers will be inversely related to perceived loneliness. The following hypothesis is developed.

Hypothesis5: Perceived social involvement has a negative effect on perceived loneliness.

Social involvement can influence mood (e.g., Gore, Aseltine, and Colten 1993; Klumb 2004; Lu 1999). People included in a social context, such as a company, are more likely to have a positive mood than those who are alone (Klumb 2004). For older people, social support enhances happiness and positive mood (Lu 1999). Therefore, it is expected that a positive relationship between perceived social involvement and positive mood of older consumers. The following hypothesis is developed.

Hypothesis. : Perceived social involvement has a positive effect on positive mood.

Loneliness may be a painful and stressful experience (Rokach 2004) often influenced by the death of close friends or family members, fewer neighbor visitors, and less participation in social activities for older people (Adams, Sanders, and Auth 2004). These causes of loneliness contribute to negative experiences in later life. Several researchers (Holmen, Ericsson, and Winblad 1999; Groothof 2004) found a negative relationship between perceived loneliness and a positive mood state. In particular, loneliness had a negative effect on the mood state of older people (Holmen et al. 1999). Those who were lonely were likely to experience a negative mood state (Groothof 2004; Holmen et al. 1999). Based on the literature, it is expected that as older consumers feel less lonely in shopping via television, their mood is likely to be positive. Therefore, the following hypothesis is generated.

Hypothesis7: Perceived loneliness has a negative effect on positive mood.

\subsection{Effect of Positive Mood on Perceived Risk and Unplanned Buying}

Despite the significant growth of television home shopping, some obstacles for selling products still exist. When consumers make a purchase decision about a product on a television shopping programs, they may experience uncertainty in their decision due to a lack of physical product contact. Several studies (e.g., Kim and Lennon 2000; McCorkle 1990) reported that the main concern of television home shopping 
is the inability to examine and evaluate merchandise before making a purchase. Uncertainty may be strongly related to the inability to inspect products and service quality (McCorkle 1990). In fact, the merchandise return rate of 20 to $40 \%$ in television home shopping in the US may result from the inability to inspect apparel physically (Jasper and Ouellette 1994; Kim and Lennon 2000; Solomon 1994). Kim and Lennon (2000) found the main reason for returning products was the product received did not meet expectations. Physical experience with the product prior to purchase, especially for apparel products, is required (Kwon, Paek, and Arzeni 1991), but is not available in television home shopping. Thus, the absence of physical experience with the product strongly influences television shoppers' perceived risk and, in turn, purchase intention (Kim and Lennon 2000). The relationship between perceived risk and purchase intention has been a focus of in-home shopping studies, including telephone shopping (Cox and Rich 1964), catalog purchases (Gaal and Burns 2005; Jasper and Ouellette 1994), television shopping (Kim and Lennon 2000; Stanforth, Lennon, and Moore 2000), and Internet apparel shopping (Park et al. 2005).

A consumer's positive mood state may lead to a positive evaluation of a product by reducing perceived risk. A positive mood was negatively related to perceived risk (Arjun 1997). Park, Lennon, and Stoel (2005) found that consum- ers in positive moods perceived less risk than those in negative moods in an on-line apparel shopping environment (Park et al. 2005). Consumers in positive moods may evaluate risk situations more optimistically. Moreover, individuals with negative moods were less willing to take risk (Williams et al. 2003). Based on the literature, it is reasonable to expect that a positive mood state may reduce the level of perceived risk in purchasing products from television shopping program. Therefore, the following hypothesis is proposed:

Hypothesiss: Positive mood negatively affects perceived risk of purchasing a product via television shopping program.

Consumers perceive television home shopping as a high-risk shopping environment. Due to the nature of the television shopping environment (e.g., products are presented for only 30 minutes, specific products are not announced in the program guide), consumers are not able to plan to purchase before they watch television shopping programs (Lennon and Sanik 2003). Purchase from television shopping programs is unplanned.

Unplanned buying is strongly affected by mood (Weinberg and Gottwald 1982). Several researchers examined the effect of customers' mood state on their purchase behavior (Gardner 1985; Park et al. 2005) and unplanned buying (Rook and Gardner 1993). Customers in a positive mood 
are more willing to try on clothing than those who are in a negative mood (Gardner 1985). Park et al. (2005) also found those who are in a positive mood are more willing to purchase. A pleasurable mood state also is a stronger antecedent to unplanned buying than carefree, exciting, and powerful mood states (Rook and Gardner 1993). Therefore, there may be a positive relationship between customers' mood and unplanned buying behavior in the television home shopping environment. The following hypothesis is developed:

Hypothesisg: Positive mood has a positive effect on unplanned buying.

In television home shopping, a decrease in risk perceived may lead to more purchases (Burgess 2003). Kim and Lennon (2000) found that purchase intention increases when perceived risk decreases during television home shopping. The greater the level of perceived risk, the less the customer is willing to pay for the product (Tsiros and Heilman 2005). When television shoppers feel less risk associated with purchasing apparel, impulse purchases increase (Park and Lennon 2004). Older people who perceive less risk may be more willing to try a new product (Schiffman 1972). Based on the literature, it is expected that perceived risk can negatively influence unplanned buying via television shopping program. Therefore, the following hypothesis is developed.

Hypothesis 10 : Perceived risk of purchasing a product via television shopping program negatively affects unplanned buying.

Based on the literature review, a proposed model is presented in Figure 1.

\section{$\langle$ Figure 1〉 The proposed model}

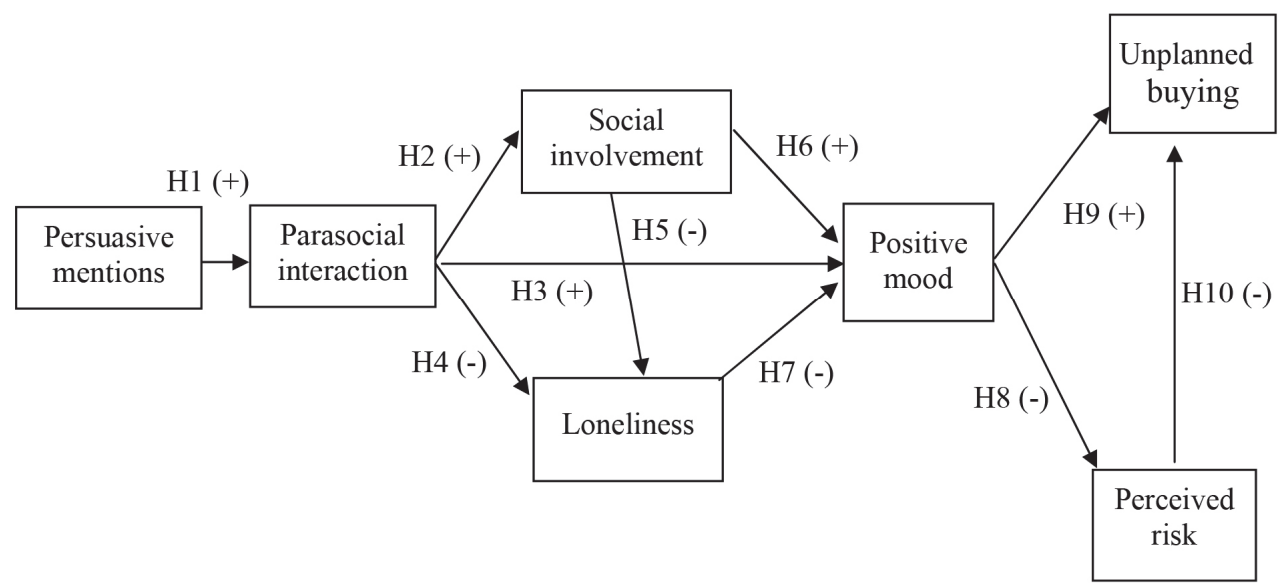




\section{Method}

\subsection{Sampling Procedure}

Two different sampling methods were used in this study because of a low response rate in the initial method. Elderly women (55 and older) who had experience with television home shopping programs were recruited through a variety of churches, senior centers, or senior agencies in central and eastern Iowa in the initial sample. To increase the number of respondents, a mail survey was sent to 200 women (55 to 80) drawn from a list of college alumni of a major Midwestern university. If these elderly women had never watched a television home shopping program, they were asked to watch any television home shopping program at least once and then complete the survey.

For the first stage of sampling, we approached 10 administrators from churches, senior centers, and senior agencies via mail, and then visited the administrators at their central Iowa locations to personally request permission to obtain the data from their members/clients. Once approval was acquired, we provided invitation letters /announcements to be shared with members/ clients. After obtaining permission to visit the agencies, a date with the administrators to visit each church, senior center, and senior agency was set up. Administrators assisted in identifying women who were television home shoppers and helped recruit participants prior to the researchers' visit.

On the scheduled dates, we visited the agencies and collected the data from those who were television home shopping shoppers, between the ages of 55 to 80, and who agreed to participate. Human Subjects information was provided along with a description of the purpose of the study. Individuals who agreed to participate completed the questionnaire and then left their signed consent form and contact information with the completed questionnaire. The instruments did not contain the names of participants. Rather, identification numbers were assigned to questionnaires completed by participants. In this sampling 117 surveys were distributed and 59 responses were collected.

For the second stage of the sampling, the survey used in the first stage of sampling was mailed to two hundred randomly selected female members of a college alumni list, who were aged 55 to 80. An invitation flyer, a copy of the questionnaire, and a postage-paid selfaddressed return envelope were mailed to the 200 Alumni members. Due to limitations in research funds, a reminder letter and another questionnaire were not distributed. After a month, 75 questionnaires had been received. Fifty usable questionnaires were retained, after incomplete questionnaires were removed. Compensation was not offered to either sample. 


\subsection{Instrument}

The present study focuses on the four more frequently used persuasive mentions of the host: Social proof, liking, authority, and scarcity. A fourteen-item scale of four persuasive strategies proposed by Cialdini (1993) was used. To measure perceived parasocial interactions between hosts and viewers, seven items originally developed by Levy (1979) and modified by Park and Lennon (2004) were used. Eight items selected from the Social Provisions Scale was used to assess social involvement (Cutrona and Russell 1987). To assess the perceived loneliness, ten items of the UCLA Loneliness Scale (Version 3) was used (Russell 1996). Izard's (1972) three-item scale measured positive mood state. To measure unplanned buying, a tenitem scale (Weun, Jones, and Beatty 1997) was used. Social involvement and perceived loneliness were measured on a 4-point Likerttype scale from 1 (Strongly disagree; Lonely; Never) to 4 (Strongly agree; Non-lonely; Always). An even-numbered scale eliminating the midpoint (neutral, neither, nor, uncertain, etc.) was used, in order to avoid social desirability bias (Garland 1991). Respondents were forced to reveal their true psychological state of social involvement and loneliness. Other items were measured using a 5-point Likert-type response scale ranging from 1 (Strongly disagree; Not at all) to 5 (Strongly agree: Very strongly). All items were revised to reflect the television shopping context. The consent form and questionnaire were pre-tested using ten faculty and staff members (55 and older) to identify any wording, procedural, or format problems (e.g., font size) and to confirm the length of time needed to complete the questionnaire prior to collecting data for this study. Demographic information, health status, and television shopping experience were also collected.

\section{Results}

\subsection{Respondent Profile}

A total of 109 usable responses from female television shoppers aged 55 to 80 were retained for data analyses. The largest percentage of participants was aged 55 to $64(57.8 \%)$, followed by those aged 75 and over $(22.9 \%)$ and those aged 65 to 74 (19.3\%). The majority of the respondents were White or European (92.5 $\%)$, followed by Native American (3.7\%), Asian American (1.9\%), Black or African American $(0.9 \%)$, and two or more races $(0.9 \%)$. Over $60 \%$ of the participants were married, about $18 \%$ were widowed, $14 \%$ were divorced, and $3 \%$ were never married. About $50 \%$ of the respondents were retired and 50\% were working full/part time. About $40 \%$ of the participants reported less than $\$ 50,000$ annual income, while the remaining $60 \%$ reported over $\$ 50,000$ an- 
nual income. The majority watched television shopping programs less than once a month (67.3\%), followed by 1 to 2 times a month (15.0\%), once a week (7.5\%), everyday (5.6\%), and 2 to 3 times a week (4.7\%). About 51.9\% of participants never purchased from television shopping programs. Whereas, $18.5 \%$ of $\mathrm{re}^{-}$ spondents bought products from television home shopping programs 1 to 2 times a year, followed by less than once a year $(15.7 \%), 3$ to 4 times a year $(5.6 \%)$, more than once a month $(4.6 \%)$, and 5 to 6 times a year $(3.7 \%)$. Most of the respondents watched QVC (66.1 $\%)$, followed by HSN (47.7 \%), JTV (3.7\%), and ShopNBC (2.8\%). About 53\% of the participants had never bought a product from television shopping channels; $19.5 \%$ of the respondents bought apparel from television shopping channels, followed by jewelry (17.4\%), decorative items (16.5\%), kitchen appliances $(16.5 \%)$, others $(14.7 \%)$, bedding $(12.8 \%)$, cosmetics (11.9\%), electronics (10.1\%), home improvement (8.3\%), shoes (7.3\%), and food (5.5).

\subsection{Preliminary Analyses}

Exploratory factor analysis using a principal axis factoring method with varimax rotation was conducted to determine the multi-item structure of the variables. Items with standardized loading estimates, which are above .55 (Nunnally 1967) and not higher than .30 on other factors (Kline 1998), were considered as evidence of the construct validity. Items that did not satisfy the standard were excluded for further analyses (see Table 1). Cronbach alpha coefficients above .70 were used as a measure of internal consistency of the multi-item variables (Nunnally 1978). The means of the summated multiple items in each variable were used to create all research variables for hypothesis testing.

\subsection{Path Model Testing}

A proposed path model was tested using a maximum-likelihood estimation procedure using AMOS 21.0. To assess the overall fit of the hypothesized model to the data, a Chi-square statistic, goodness-of-fit index (GFI $\geq .90)$, adjusted goodness of fit index (AGFI $\geq .90$ ), comparative fit index $(\mathrm{CFI} \geq .90)$, and root mean square error of approximation (RMSEA $\leq .05)$ were used. A Chi-square statistic was used as a function of the maximum likelihood estimator for the parameters and a value close to zero indicates a good fit of the model (Browne and Cudeck 1993; Schumacker and Lomax 1996).

Three models were tested-the proposed model, the fully recursive model, and the empirical model. The fully recursive model was run after the proposed model resulted in marginal fit. The fully recursive model identified the statistically significant paths. The results of both the proposed model and the fully recursive 
$\langle$ Table 1〉 Exploratory factor analysis for construct validity $(n=109)$

\begin{tabular}{|c|c|}
\hline $\begin{array}{ll} & \text { Variables } \\
\end{array}$ & Loadings \\
\hline $\begin{array}{l}\text { Persuasive mentions (Cialdini 1993) } \\
\text { The hosts inform the viewer that the product they are selling is one of the best sellers. } \\
\text { The hosts explain the level of popularity of the product. } \\
\text { The hosts inform me that an item that was popular in a past show is now available for purchase. } \\
\text { The hosts mention that there are a limited number of the products lefts. } \\
\text { The hosts tell me that the product is almost sold out. } \\
\text { The hosts mention that this is last chance for me to purchase a product. } \\
\quad \text { Eigenvalue }=3.84 ; \% \text { of variance }=38.43\end{array}$ & $\begin{array}{l}.69 \\
.68 \\
.61 \\
.90 \\
.91 \\
.86\end{array}$ \\
\hline $\begin{array}{l}\text { Parasocial interaction (Levy 1979; Park and Lennon 2004) } \\
\text { The hosts are almost like friends I see everyday. } \\
\text { I like hearing the voices of the hosts in my home. } \\
\text { When the hosts show how they feel about the product, it helps me make up my mind about the products. } \\
\text { I like to compare my feelings for the product with what the hosts say about it. } \\
\text { When the hosts joke around with each other, it makes the program even more enjoyable. } \\
\text { The hosts show me what people in the media are really like. } \\
\text { I feel sorry for the hosts when they make mistakes. } \\
\quad \text { Eigenvalue }=3.94 ; \% \text { of variance }=56.27\end{array}$ & $\begin{array}{l}.81 \\
.85 \\
.84 \\
.71 \\
.78 \\
.59 \\
.64\end{array}$ \\
\hline $\begin{array}{l}\text { Social involvement (Cutrona and Russell 1987) } \\
\text { When watching television shopping programs, } \\
\text { I believe there are people who depend on me for help. } \\
\text { I feel part of the group of people who share my attitudes and beliefs. } \\
\text { I believe I have close relationships that provide me with a sense of emotional security and well-being. } \\
\text { I feel a strong emotional bond with at least one other person. } \\
\text { Eigenvalue }=3.04 \% \% \text { of variance }=38.04\end{array}$ & $\begin{array}{l}.75 \\
.85 \\
.96 \\
.90\end{array}$ \\
\hline $\begin{array}{l}\text { Perceived loneliness (Russell 1996) } \\
\text { When watching television shopping programs, } \\
\text { I feel I have a lot in common with other people. } \\
\text { I feel close to people. } \\
\text { I feel there are people who really understand me. } \\
\text { I feel there are people I can talk to. } \\
\text { I feel there are people I can turn to. } \\
\text { Eigenvalue }=3.43 ; \% \text { of variance }=38.05\end{array}$ & $\begin{array}{l}.68 \\
.63 \\
.89 \\
.92 \\
.93\end{array}$ \\
\hline $\begin{array}{l}\text { Mood (Izard 1972) } \\
\text { Happy } \\
\text { Delighted } \\
\text { Joyful } \\
\text { Eigenvalue }=2.69 ; \% \text { of variance }=44.85\end{array}$ & $\begin{array}{l}.94 \\
.92 \\
.94\end{array}$ \\
\hline $\begin{array}{l}\text { Perceived risk (Kwon et al. 1991) } \\
\text { Products purchased from TV home shopping programs will not be the same as shown on TV. } \\
\text { Products purchased from TV home shopping programs will not be in fashion. } \\
\text { Products purchased from TV home shopping programs will not fit. } \\
\text { Products purchased from TV home shopping programs will not fit into my existing wardrobe. } \\
\text { Eigenvalue }=2.68 ; \% \text { of variance }=33.54\end{array}$ & $\begin{array}{l}.80 \\
.83 \\
.83 \\
.73\end{array}$ \\
\hline $\begin{array}{l}\text { Unplanned buying (Weun, Jones, and Beatty 1997) } \\
\text { If a TV shopping show introduces something new that really interests me, } \\
\text { I buy it right away just to see what it is like. } \\
\text { I buy it without considering the consequences. } \\
\text { I may buy things from a TV shopping show without hesitation if I like them when I first see them. } \\
\text { If a TV shopping show introduces something new and I really want, I purchase it immediately, even if I } \\
\text { had not planned to buy it. } \\
\text { I can make unplanned purchases from a TV shopping show. } \\
\text { Eigenvalue }=3.40 \text {; } \% \text { of variance }=42.45\end{array}$ & $\begin{array}{l}.86 \\
.68 \\
.88 \\
.84 \\
.72\end{array}$ \\
\hline
\end{tabular}


model are presented in Table 2. The empirical model, which included the two additional statistically significant paths identified in the fully recursive model, was used for hypothesis testing.

\subsubsection{The proposed model and the fully recursive model}

The proposed model was first tested and the results indicated that overall fit indices were marginal. The results revealed a $x^{2}$ of 35.82 with 11 degrees-of-freedom $(p<.01)$. The GFI was .92; AGFI was .80; CFI was .89; and RMSEA was .15. These results indicated that the proposed model did not fully explain the data. Therefore, the fully recursive model was examined and revealed a $x^{2}$ of 0.00 with 0 de- $^{-}$ grees-of-freedom. The GFI was 1.00, CFI was 1.00 .

Standardized path estimates, critical values, and square multiple correlations for both the proposed model and the fully recursive model are shown in Table 2. The proposed model and the fully recursive model resulted in two significant differences. First, mood had significant effects on perceived risk and unplanned buying in the proposed model $(\beta=-.22, C . R$. $=$ -2.29, $p<.05 ; \beta=.22$, C.R. $=2.52, p<.05$, respectively) whereas mood had no significant effects on perceived risk and unplanned buying in the fully recursive model $(\beta=-.03, C . R$. $=$ $-.28 ; \beta=.05, C . R .=.46$, respectively). From the fully recursive model two statistically significant paths, not included in the proposed

〈Table 2〉 Path estimates for the proposed model and the fully recursive model

\begin{tabular}{|c|c|c|c|c|c|c|c|c|c|c|c|}
\hline \multirow[t]{2}{*}{$\begin{array}{l}\text { Predictor } \\
\text { variables }\end{array}$} & \multirow{2}{*}{$\begin{array}{c}\text { Parasocial } \\
\text { interaction }\end{array}$} & \multicolumn{2}{|c|}{$\begin{array}{c}\text { Social } \\
\text { involvement }\end{array}$} & \multicolumn{2}{|c|}{ Loneliness } & \multicolumn{2}{|c|}{ Mood } & \multicolumn{2}{|c|}{ Perceived risk } & \multicolumn{2}{|c|}{$\begin{array}{l}\text { Unplanned } \\
\text { buying }\end{array}$} \\
\hline & & M1 & M2 & M1 & M2 & M1 & $\mathrm{M} 2$ & M1 & M2 & M1 & M2 \\
\hline $\begin{array}{l}\text { Persuasive } \\
\text { mentions }\end{array}$ & $\begin{array}{c}.15 \\
(1.52)\end{array}$ & & $\begin{array}{l}-.04 \\
(-.51)\end{array}$ & & $\begin{array}{c}-.03 \\
(-.40)\end{array}$ & & $\begin{array}{l}.02 \\
(.25)\end{array}$ & & $\begin{array}{c}-.10 \\
(-1.08)\end{array}$ & & $\begin{array}{c}-.13 \\
(-1.61)\end{array}$ \\
\hline $\begin{array}{l}\text { Parasocial } \\
\text { interaction }\end{array}$ & & $\begin{array}{l}.44^{* *} \\
(5.10)\end{array}$ & $\begin{array}{c}.45^{* *} \\
(5.10)\end{array}$ & $\begin{array}{c}-.09 \\
(-1.30)\end{array}$ & $\begin{array}{c}-.08 \\
(-1.21)\end{array}$ & $\begin{array}{l}.28^{* *} \\
(3.35)\end{array}$ & $\begin{array}{l}.28^{* *} \\
(3.28)\end{array}$ & & $\begin{array}{l}-.39 * * \\
(-3.80)\end{array}$ & & $\begin{array}{l}.41^{* *} \\
(4.13)\end{array}$ \\
\hline $\begin{array}{l}\text { Social } \\
\text { involvement }\end{array}$ & & & & $\begin{array}{c}-.74^{* *} \\
(-11.18)\end{array}$ & $\begin{array}{c}-.74^{* *} \\
(-11.21)\end{array}$ & $\begin{array}{c}.17 \\
(1.39)\end{array}$ & $\begin{array}{c}.17 \\
(1.41)\end{array}$ & & $\begin{array}{l}-.05 \\
(-.31)\end{array}$ & & $\begin{array}{l}.01 \\
(.09)\end{array}$ \\
\hline Loneliness & & & & & & $\begin{array}{c}-.29 * \\
(-2.37)\end{array}$ & $\begin{array}{c}-.29 * \\
(-2.36)\end{array}$ & & $\begin{array}{l}-.07 \\
(-.46)\end{array}$ & & $\begin{array}{l}-.02 \\
(-.13)\end{array}$ \\
\hline Mood & & & & & & & & $\begin{array}{c}-.22^{*} \\
(-2.29)\end{array}$ & $\begin{array}{c}-.03 \\
(-.28)\end{array}$ & $\begin{array}{c}.22^{*} \\
(2.52)\end{array}$ & $\begin{array}{l}.05 \\
(.46)\end{array}$ \\
\hline $\begin{array}{l}\text { Perceived } \\
\text { risk }\end{array}$ & & & & & & & & & & $\begin{array}{l}-.37^{* *} \\
(-4.22)\end{array}$ & $\begin{array}{l}-.25^{* *} \\
(-2.91)\end{array}$ \\
\hline$R^{2}$ & .02 & .19 & .20 & .62 & .62 & .38 & .38 & .05 & .18 & .22 & .34 \\
\hline
\end{tabular}

Notes: Standardized path estimates are reported with critical ratio (C.R.) in parentheses. M1 refers to the proposed model; M2 refers to the fully recursive model $* p<.05 . * * p<.01$. 
model, were found. Parasocial interaction with television home shopping show hosts had significant effects on perceived risk and unplanned buying $(\beta=-.39, C . R .=-3.80, p<.01 ; \beta=$ .41, C.R. $=4.13, p<.01$, respectively). These two significant paths were added to the empirical model. The present study tested the hypothesized relationships using the empirical model.

\subsubsection{The empirical model}

The empirical model was tested after two significant paths identified in the fully $\mathrm{re}^{-}$ cursive model were added. The results revealed a $x^{2}$ of 4.48 with 9 degrees-of-freedom ( $p=$ .88). The GFI was .99; AGFI was .96; CFI was 1.00; and RMSEA was .00. The fit indices showed the data fit the empirical model very well with the two added significant paths from perceived parasocial interaction to perceived risk and unplanned buying tendency. Path coefficients, critical ratios (C.R.), and squared multiple correlations $\left(R^{2}\right)$ for the empirical model were reported in Figure 2. The proposed positive effect for persuasive mentions of the host on parasocial interaction was not significant

〈Figure 2〉 The final empirical model

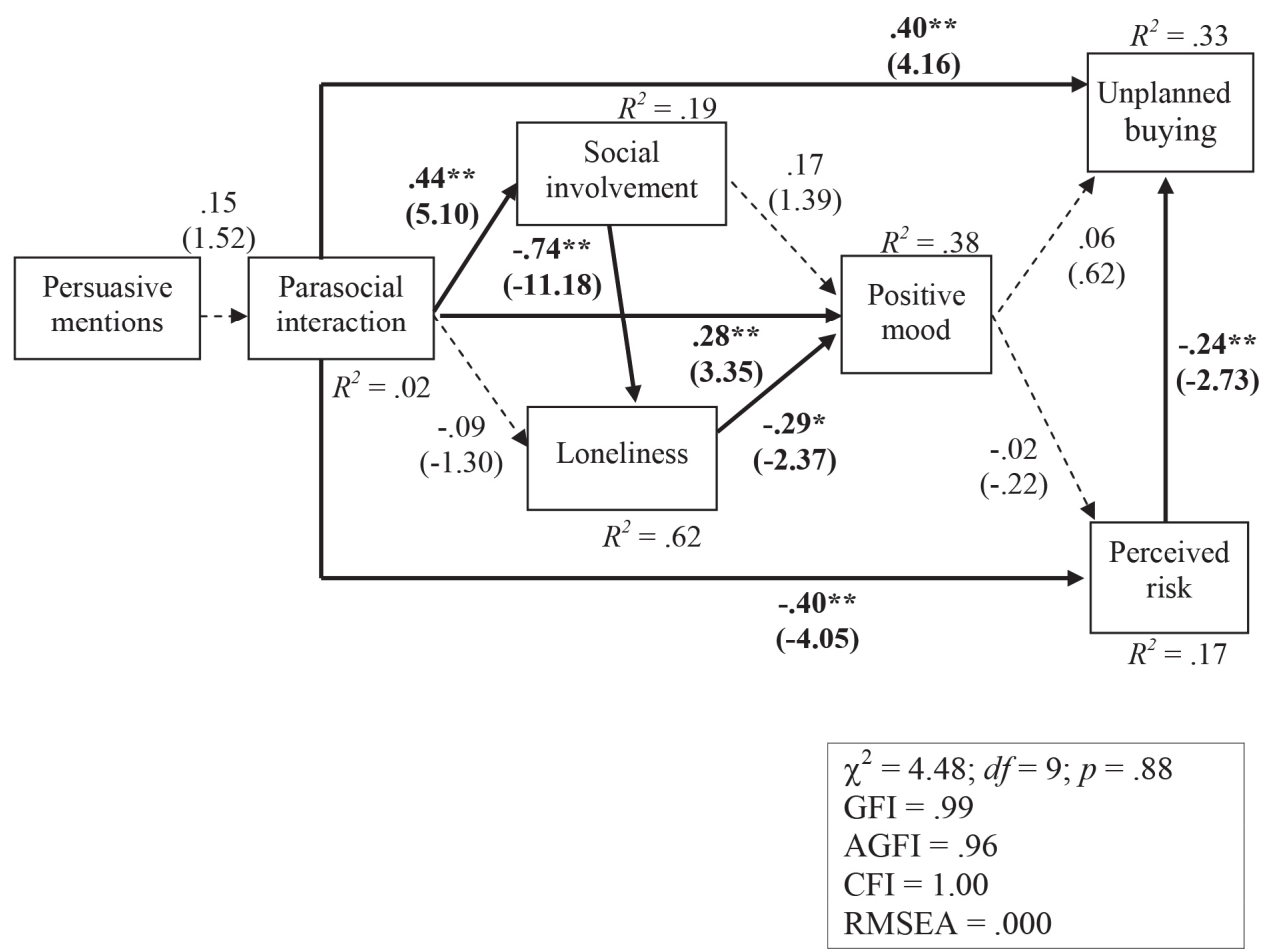

Notes: Standardized path estimates are reported with critical ratio (C.R.) in parentheses.

$* p<.05 . * * p<.01$. 
$\left(\mathrm{H}_{1 \text { Rejected }}: \beta_{1}=.15\right.$, C.R. $\left.=1.52, p=.21\right)$, indicating that persuasive mentions did not positively influence parasocial interaction. Parasocial interaction positively affected social involvement $\left(\mathrm{H}_{2 \text { supported }}: \beta_{2}=.44\right.$, C.R. $=5.10, p<$ $.01)$ and $\operatorname{mood}\left(\mathrm{H}_{3}\right.$ supported $: \beta_{3}=.28$, C.R. $=$ 3.35, $p<.01)$, but did not have a significant effect on loneliness $\left(\mathrm{H}_{4}\right.$ rejected $: \beta_{4}=-.09$, C.R. $=-1.30, p=.22)$. Perceived social involvement had a significant effect on loneliness $\left(\mathrm{H}_{5}\right.$ supported $: \beta_{5}=-.74$, C.R. $\left.=-11.18, p<.01\right)$ but not on mood $\left(\mathrm{H}_{6 \text { rejected }}: \beta_{6}=.17\right.$, C.R. $=1.39$, $p=.29)$. Loneliness negatively affected mood of older consumers $\left(\mathrm{H}_{7}\right.$ supported $: \beta_{7}=-.29$, C.R. $=-2.37, p<.05)$. Mood, however, did not influence perceived risk $\left(\mathrm{H}_{8}\right.$ rejected $: \beta_{8}=-.02$, C.R. $=-.22, p=.84)$ and unplanned buying $\left(\mathrm{H}_{9}\right.$ rejected $\left.: \beta_{9}=.06, C . R .=.62, p=.53\right)$. Perceived risk had a significant negative effect on unplanned buying $\left(\mathrm{H}_{10}\right.$ supported $: \beta_{10}=-.24$, C.R. $=-2.73, p<.01)$.

\section{Discussions and Implications}

This study investigated the effects of persuasive mentions and parasocial interactions on social involvement, loneliness, positive mood, perceived risk, and unplanned buying tendency among older female shoppers in the television shopping environment. Use of persuasive mentions was expected to directly affect shoppers' parasocial interaction with the host when shopping on TV. However, the effect of persuasive mentions of the host on parasocial interaction was not significant. It is possible that the amount of persuasive mentions may not directly influence parasocial interaction. Rather, the matter of how much elderly consumers trust or credit on persuasive mentions can influence parasocial interaction. Also, the quality of prior TV shopping experience or dependency toward the TV shopping channels may have a stronger effect on parasocial interaction than persuasive mentions. Park and Lennon (2004) found that parasocial interaction is likely to be formed with frequent exposure to TV shopping channels. The amount of persuasive mentions may strengthen or weaken the relationship between prior TV shopping experience and parasocial interaction.

Yet, the results indicated that parasocial interaction with the host significantly influenced older consumers' social involvement and loneliness. Older consumers who were likely to parasocially interact with the television shopping show hosts believed they were more socially involved. This finding is consistent with Levy's (1979) findings, which showed parasocial interaction with a media personality had a positive influence on older viewer's perceived social involvement. Also, consistent with previous research (Johnson-Hillery and Kang 1997), the present findings revealed that parasocial interaction was associated with the positive mood state of older consumers. When older people perceived higher parasocial inter- 
actions with the television home shopping host, they reported being in a more positive mood.

Inconsistent with earlier findings (Levy 1979; Rubin et al. 1985), a significant negative association between parasocial interaction and loneliness was not found. Parasocial interaction did not have a significant effect on loneliness, but social involvement did have a significant effect on loneliness, which may have resulted in a mediating effect. Kraus, Davis, Bazzini, Church, and Kirchman (1993) examined the effects of personal and social interaction factors on loneliness, before/after controlling for the effect of social involvement. They found the mediating effect of social involvement between personal and social interactions and loneliness.

Inconsistent with previous research (Klumb 2004; Lu 1999), social involvement did not enhance mood among older women, but loneliness had a significant negative effect on positive mood. Again, a non-significant effect of social involvement on positive mood might be due to the mediating effect of loneliness. Even though a significant direct effect of social involvement on mood was not found, the results showed a significant indirect effect of social involvement, which is mediated by loneliness, on mood. Several studies (Groothof 2004; Holmen, Ericsson, and Winblad 1999) have found a negative relationship between loneliness and a positive mood state. In particular, Holmen et al. (1999) found that loneliness had a negative effect on the positive mood states of older individuals. Moreover, the results showed that social involvement had a significant negative effect on loneliness among older female television home shopping shoppers. This is consistent with Kim et al.'s (2005) finding that older consumers, who had less social involvement, were likely to feel lonelier than those who had greater social involvement. Yet, it is important to mention that Kim et al. (2005) examined person-to-person relationships; whereas, this study focused on a viewer's perceived relationship with television home shopping hosts through the media.

Perceived risk had a significant effect on unplanned buying. This result supports Park and Lennon's (2004) finding that unplanned buying increases when television shoppers feel less risk associated with products. However, positive mood did not influence unplanned buying, which contradicts previous research (Rook and Gardner 1993). This may result from the characteristics of older consumers. Older consumers are likely to shop with specific purposes; whereas, younger consumers are more likely to make unplanned buying behavior in response to mood (DeNora and Belcher 2000).

The present study found two interesting associations between variables, which were not hypothesized. First, there was a significant negative effect of parasocial interaction on perceived risk. Dholakia (2001) mentioned that perceived risk increases when significant other people have unfavorable opinions about a product. In the television home shopping environment, if 
a viewer received a favorable opinion of the television home shopping host, who is perceived as a friend through parasocial interaction, a viewer's perceived risk would decrease. Thus, television home shoppers, who formed parasocial interactions with hosts, were less likely to perceive a risk of purchasing a product.

Second, a significant positive effect of parasocial interaction on unplanned buying was found. This supports Stephens et al.'s (1996) study, which analyzed conversations between television home shopping hosts and viewers of QVC programs. In their study, television home shopping hosts tried to create parasocial interactions with viewers, while selling products, and viewers indicated their increased unplanned buying experiences when television home shopping hosts encouraged them to buy a product. This study has some limitations. The elderly consumer data was collected in the late 2000s, when the television shopping industry in the U.S. reached a maturity stage in its market size and sales volume. In the recent years, TV shopping channels are evolving with the Internet and mobile technology. Further research needs to reflect such change in the market and investigate the effect of social and physical limitations on the single channel vs. multiple channel choice behavior among the elderly consumers.

Respondents were asked to think of the situation when they watch television home shopping programs. For example, the item "when watching television shopping programs, I feel a lack of companionship" was used to capture respondents' feelings about the television home shopping programs they usually watch. Thus, the respondents had to depend on memory when they answered the questions. In particular, because mood is temporal, it may not be accurately recalled from memory.

Several recommendations for television home shopping retailers and future research are suggested, based on this study. It is important to focus a relationship with middle-aged and older consumers and encourage them to watching television home shopping programs. The effects of perceived parasocial interaction with the hosts could be bolstered through live experiences, such as actually meeting favorite hosts during promotional tours. The television home shopping industry should further strengthen parasocial interactions through various marketing efforts. For example, if the hosts offer products that reflect issues important to the demographic, such as a line of apparel with a portion of profits supporting women's breast cancer or heart disease research, it may strengthen customers' perceived parasocial interaction and increase sales. At present, older women are more likely to shop via television shopping programs than younger consumers. To extend their consumer base, perhaps hosts popular among younger consumers and promoted on websites and TV channels attractive to these younger consumers could attract a new audience. In addition, new program formats using technology popular among 
these consumers, such as iPods and cell phones, could be explored.

The present study did not support the past research, which found persuasive communication strategies to have a significant impact on parasocial interaction. Future research can differentiate six types of persuasive mentions of the host and examine the effect of each type of persuasive mentions on parasocial interaction. Perhaps the effect of scarcity is diluted when other persuasive mentions are added for certain product categories or used with certain target markets. In addition, this study found a significant effect of parasocial interaction on social involvement. Older people may perceive a host to be a friend through parasocial interaction leading to an increase in social involvement. Future studies may examine this effect among consumers with different levels of disposable income. Those who have more income to re- $^{-}$ spond to the advice of the host (i.e., purchase products) may be likely to feel more socially involved via parasocial interactions with the host; whereas, those who are not able to fully participate through the purchase of products more likely to experience a diminished sense of social involvement, decreased mood, and increased loneliness.

〈Received February 14. 2017〉

〈Accepted February 15. 2017〉

\section{References}

Adams, Kathryn B., S. Sanders, and E. A. Auth (2004), "Loneliness and depression in independent living retirement communities: Risk and resilience factors," Aging and Mental Health, 8 (6), 475-85.

Andrade, Eduardo B (2005), "Behavioral consequences of affect: Combining evaluative and regulatory mechanisms," Journal of Consumer Research, 32 (3), 355-62.

Auter, Philip J. and Roy L. Moore (1993), "Buying from a friend: A content analysis of two teleshopping programs," Journalism Quarterly, 70 (2), 425-36.

Braus, Patricia (1990), "What is good service?," American Demographics, 12 (7), 36-39.

Browne, Michael W. and Robert Cudeck (1993), "Alternative ways of assessing model fit," In Testing Structural Equation Models, Kenneth A. Bollen and J. Scott Long, eds. Newbury Park: Sage publications, 136-162. Burgess, Brigitte (2003), “A comparison of TV home shoppers based on risk perception," Journal of Fashion Marketing and $\mathrm{Ma}^{-}$ nagement, 7 (3), 259-71.

Cattan, Mima, Martin White, John Bond, and Alison Learmouth (2005), "Preventing social isolation and loneliness among older people: A systematic review of health promotion interventions," Aging and Society, 25 (1), 41-67. 
Chaudhuri, Arjun (1997), "Consumption emotion and perceived risk: A macro-analytic approach," Journal of Business Research, 39 (2), 81-92.

Cialdini, Robert B. (1984), "Principles of Automatic Influence," In Personal Selling: Theory, Research, and Practice, Jacob Jacoby and C. Samuel Craig, eds. Lexington: Lexington Books, 1-28.

(1993), Influence: Science

and practice. New York: Harper Collins College.

and Noah J. Goldstein (2002),

"The science and practice of persuasion," Cornell Hotel and Restaurant Administration Quarterly, 43 (2), 40-50.

Conway, Joseph C. and Alan M. Rubin (1991), "Psychological predictors of television viewing motivation," Communication Research, 18 (4), 443-63.

Cox, Donald F. and Stuart U. Rich (1964), "Perceived risk and consumer decisionmaking: The case of telephone shopping," Journal of Marketing Research, 1 (4), 3239.

Cutrona, Carolyn E and Daniel W. Russell (1987), "The provisions of social relationships and adaptation to stress," Advances in Personal Relationships, 1, 37-67.

DeNora, Tia. and Sophie Belcher (2000), "When you're trying something on you picture yourself in a place where they are playing this kind of music-musically sponsored agency in the British clothing retail sector," Sociological Review, 48 (1), 80-101.

Dholakia, Utpal M. (2001), "A motivational process model of product involvement and consumer risk perception," European Journal of Marketing, 35 (11/12), 1340-62.

Diener, Ed (2000), "Subjective well-being: Three decades of progress," American Psychologist, 55 (1), 34-43.

Fritchie, Louise Lystig and Kim K.P. Johnson (2003), "Personal selling approaches used in television shopping," Journal of Fashion Marketing and Management, 7 (3), 249-58.

Gaal, Brigitte and Leslie Davis Burns (2005), "Apparel descriptions in catalogs and perceived risk associated with catalog purchases," Clothing and Textiles Research Journal, 19 (1), 22-30.

Gardner, Meryl Paula (1985), "Mood states and consumer behavior: A critical review," Journal of Consumer Research, 12 (3), 281300.

Garland, Ron (1991), "The mid-point on a rating scale: Is it desirable?" Marketing Bulletin, 2, 66-70.

Gibson, Hamilton (2000), Loneliness in later life. New York: St. Martins.

Gore, Susan, Robert H. Aseltine Jr., and Mary Ellen Colten (1993), "Gender, social-relational involvement, and depression," Journal of research on adolescence, 3 (2), 101-25.

Gorn, Gerald, Marvin Goldberg, and Kunal Basu (1993), "Mood, awareness, and product 
evaluation," Journal of Consumer Psychology, 2 (3), 237-56.

Grant, August E., Kendall Guthrie, and Sandra J. Ball-Rokeach (1991), "Television Shopping: A media system dependency perspective," Communication Research, 18 (6), 773-98.

Groothof, H. (2004), "When others are doing better or worse: Responses from the heart and the head," doctoral dissertation, University of Groningen.

Holmén, Karin, Kjerstin Ericsson, and Bengt Winblad (1999), "Quality of life among the elderly," Scandinavian Journal of Caring Sciences, 13 (2), 91-95.

InfoScout (2016), "As seen on TV consumer insights," (accessed February 14, 2017), [available at http://infoscout.co/brand/as _seen_on_tv/]

Izard, Carrolle E. (1972), Patterns of emotions: A new analysis of anxiety and depression. New York: Academic Press.

Jasper, Cynthia R. and Sara J. Ouellette (1994), "Consumers' perception of risk and the purchase of apparel from catalogs," Journal of Direct Marketing, 8 (2), 23-36.

John-Hillery, Julie L. and Jikyeong Kang (1997), Elderly consumers and retail sales personnel: Examining knowledge, attitudes and retail service satisfaction. New York: Garland.

Kaiser, Susan B. and Joan L. Chandler (1984), "Fashion alienation: Older adults and the mass media," International Journal of Aging and Human Development, 19 (3), 203-21.
Kang, Yong-Soon and Nancy Ridgway (1996), "The importance of consumer market interactions as a form of social support for elderly consumers," Journal of Public Policy and Marketing, 15 (1), 108-17.

Kim, Minjeong and Sharron J. Lennon (2000), "Television shopping for apparel in the United States: Effects of perceived amount of information on perceived risks and purchase intentions," Family and Consumer Sciences Research Journal, 28 (3), 301-30.

Kim, Young-Kyung, Jikyeong Kang, and Minsung Kim (2005), "The relationships among family and social interaction, loneliness, mall shopping motivation, and mall spending of older consumers," Psychology and Marketing, 22 (12), 995-1015.

Kline, Rex B. (1998), Principles and practice of structural equation modeling. New York: The Guilford Press.

Klumb, Petra L. (2004), "Benefits from productive and consumptive activities: Results from the Berlin aging study," Social Indicators Research, 67 (1), 107-27.

Kraus, Linda A., Mark J. Davis, Doris Bazzini, Mary Church, and Clare M. Kirchman (1993), "Personal and social influences on loneliness: The mediating effect of social provisions," Social Psychology Quarterly, 56 (1), 37-53.

Kwon, Yoon-Hee, Soae L. Paek, and Maria Arzeni (1991), "Catalog vs non-catalog shoppers of apparel: Perceived risks, shopping 
orientations, demographics, and motivations," Clothing and Textiles Research Journal, 10 (1), 13-19.

Lee, Jinkook and Loren V. Geistfeld (1999), "Elderly consumers' receptiveness to telemarketing fraud," Journal of Public Policy and Marketing, 18 (2), 208-17.

Lennon, Sharron J. and Margaret M. Sanik (2003), "Compulsive buying, parasocial interaction, and television shoppers," paper presented at the 2003 International Textiles and Apparel Association, Savannah, GA (October 27 - 31).

Levy, Mark R. (1979), "Watching TV news as para-social interaction," Journal of Broadcasting, 23 (1), 69-80.

Lim, Chae M. and Youn-Kyung Kim (2011), “Older consumers' TV home shopping: Loneliness, parasocial interaction, and perceived convenience," Psychology and Marketing, 28 (8), 763-80.

Lu, Luo (1999), "Personal or environmental causes of happiness: A longitudinal analysis," Journal of Social Psychology, 139 (1), 7990.

Manthorpe, J. (2004), "Older people," Research Matters, 20, 33-38.

McCorkle, Denny E. (1990), "The role of perceived risk in mail order catalog shopping," Journal of Direct Marketing, 4 (4), 26-35.

McDonald, William J. (1995), "Home shopping channel customer segments: A cross-cultural perspective," Journal of Direct Marketing,
9 (4), 57-67.

Nordlund, Jan-Erik (1978), "Media interaction," Communication Research, 5 (2), 150-75.

Nunnally, Jum (1978), Psychometric theory. New York: McGraw-Hill.

Park, Jihye and Sharron J. Lennon (2004), "Television apparel shopping: Impulse buying and parasocial interaction," Clothing and Textiles Research Journal, 22 (3), 135-44. , and Leslie Stoel (2005), "On-line product presentation: Effects on mood, perceived risk, and purchase intention," $P$ sychology and Marketing, 22 (9), 695-719.

Papa, MJ., A Singhal, S Law, S Pant, S Sood, EM Rogers, and CL Shefner-Rogers (2000), "Entertainment-education and social change: An analysis of parasocial interaction, social learning, collective efficacy, and paradoxical communication," Journal of Communication, 50 (4), 31-55.

Rahtz, Don R., M. Joseph Sirgy, and H. Lee Meadow, H. L. (1989), "The elderly audience: Correlates of television orientation," Journal of Advertising, 18 (3), 9-20.

Rokach, Ami (2004), "Loneliness then and now: reflections on social and emotional alienation in everyday life," Current psychology: developmental Learning Personality Social, 23 (1), 24-40.

Rook, Dennis W. and Meryl Paula Gardener (1993), "In the mood: Impulse buyings' affective antecedents," Research in Consumer Behavior, 6 (7), 1-28. 
Rubin, Alan M., Elizabeth M. Perse, and Robert A. Powell (1985), "Loneliness, parasocial interaction, and local television news viewing," Human Communication Research, 12 (2), $155-80$.

Russell, Daniel W. (1996), “UCLA loneliness scale (version 3): Reliability, validity, and factor structure," Journal of Personality Assessment, 66 (1), 20-40.

Schein, Andrew J. and Nava Haruvi (2014), "Older women, economic power, and consumerism," In Women and Aging: An International, Intersectional Power Perspective, Varda Muhlbauer, Joan C. Chrisler, and Florence L. Denmark, eds. New York: Springer, 31-49.

Schiffman, Leon G. (1972), "Perceived risk in new product trial by elderly consumers," Journal of Marketing Research, 9 (1), 10608.

Schumacher, Randall E. and Richard G. Lomax (1996), A beginner's guide to structural equation modeling. Mahwah: Lawrence Erlbaum Associates.

Skumanich, Stephanie A. and David P. Kintsfather (1998), "Individual media dependency relations within television shopping programming," Communication Research, 25 (2), 200-19.

Smith, Ruth B. and George P. Moschis (1985), "A socialization perspective on selected consumer characteristics of the elderly,"
The Journal of Consumer Affairs, 19 (1), 74-95.

Stanforth, Nancy F., Sharron J. Lennon, and S. Moore (2000), "Perceived risk and purchase intent associated with television shopping," Frontiers in Direct and Interactive Marketing Research Proceedings, 3, 53-64.

Stephens, Debra L., Ronald P. Hill, and Karyn Bergman (1996), "Enhancing the consumerproduct relationship lessons from the QVC home shopping channel," Journal of Business Research, 37 (3), 193-200.

Tsiros, Michael and Carrie M. Heilman (2005), "The effect of expiration dates and perceived risk on purchasing behavior in grocery store perishable categories," Journal of Marketing, 69 (2), 114-29.

Weinberg, P., \& Gottwald, W. (1982). Impulsive consumer buying as a result of emotions. Journal of Business Research, 10(1), 43-57. Weun, S., M. A. Jones, and S. E. Beatty (1997), "A parsimonious scale to measure impulse buying tendency," In Enhancing Knowledge Development in Marketing, Vol. 8, W.M. Pride and G.T. Hult, eds. Chicago: American Marketing Association, 306-07.

Williams, Seve, Mohamed Zainuba, and Robert Jackson (2003), "Affective influences on risk perceptions and risk intention," Journal of Managerial Psychology, 18 (2), 126-37. 